\title{
Erectile Dysfunction: A Systemic look at the Mind-Body connection in Erectile Physiology
}

\author{
Andréa Barros Ferreira Maiolino ${ }^{1}$ and Denise Von Dolinger de Brito ${ }^{1,2^{*}}$ \\ ${ }^{1}$ Health Sciences Postgraduate Program, Faculty of Medicine - Federal University of Uberlândia- MG, Brazil. \\ ${ }^{2}$ Institute of Biomedical Sciences - Federal University of Uberlândia- MG, Brazil.
}

*Corresponding author: Denise Von Dolinger de Brito, Health Sciences Postgraduate Program, Faculty of Medicine - Federal University of Uberlândia- MG, Brazil.

Received date: May 12, 2021; Accepted date: June 02, 2021; Published date: June 07,2021

Citation: Andréa B. F. Maiolino and Denise V. D. de Brito (2021). Clostridium Difficile Infection and Biliary Obstruction. J Clinical Research and Reports, 8(2); DOI:10.31579/2690-1919/173

Copyright: (C) 2021 Denise Von Dolinger de Brito, This is an open access article distributed under the Creative Commons Attribution License, which permits unrestricted use, distribution, and reproduction in any medium, provided the original work is properly cited.

\begin{abstract}
Sex is, without a doubt, an experience for the senses and, as such, it is fundamentally an experience for the "here and now". Human sexuality is a natural and poignant experience. Although they may be accentuated by words, the vitality and depth of feelings provided by sexual contact are expressed through immediate sensory experience. Despite this, few people know how to create the satisfying and rewarding sexual experiences they desire. Since sex is essentially a present and undoubtedly a sensual experience, the most important change in internal processes involves paying attention to the sensations.

This review aims to show how essential it is to have a careful attention of the patient as a whole, requiring a systemic look at him through a multidisciplinary approach, seeing the individual. Additionally, it will be shown the sexual dysfunction, as a psychosomatic being, integrating the physical and psychological evaluation, seeking data on the sexual life of the patient, relevant to the treatment of his dysfunction.

The use of such approach facilitates the obtaining of unconscious information, brought through an extremely careful interview to raise the individual internal processes; understand attitudes, external behaviors, subjective states, representative systems and beliefs, in addition to a thorough observation of the ocular access tracks of the patient with erectile dysfunction, where incongruities may arise that could otherwise be disregarded and hinder the proper treatment of the patient. All this will allow a more complete understanding of his physiological response and will facilitate the reconnection of the individual to his natural process of sexual response.
\end{abstract}

Key words: erectile dysfunction; systemic look; mind-body connection; psychosomatics; neurolinguistic programming; clinical psychology; sexual dysfunction; psychophysical experience; external stimuli

\section{Introduction}

Of all the existing sexual dysfunctions, perhaps erectile dysfunction is the most overwhelming in the male world. There is a world culture where the concept of masculinity is intrinsically linked to that of genitality [1]. Where the penis represents not only power and domination, but the very symbol of virility. For many, being a man means having a perfectly functioning penis, being able to have a full erection, being powerful [2].

Erectile disorder is defined as the persistent incapacity, total or partial, to initiate and/or maintain an erection sufficient to perform penetration and coitus until ejaculation [3]. From the emotional point of view, erectile dysfunction can cause immense problems in male selfesteem, causing emotional imbalances, states of extreme anxiety and anguish, affecting one's self-image and disfiguring one's marital relationships, and can even lead to suicide [4].
Most sexual dysfunctions are psychosomatic disorders, that is, physiological and/or structural alterations influenced by psychological processes. In this way, the importance of a multidisciplinary approach to erectile dysfunction is understood [5]. The psychosomatic or holistic model is a therapeutic view more focused on the belief that the individual reacts as a psychophysical whole [6]. There is no physical problem without psychic impairment. Likewise, emotional wear and tear can cause organic changes. It is noticeable that these disorders are evidenced, at the body level, by disturbances in the functioning of the autonomous effectors, which may be the result of a decrease or increase in physiological activity [7].

Regardless of its origin, organic, psychic or mixed, erectile dysfunction gives rise to biological stress, a damage caused to the body in response to the negative sexual experience [8]. When the individual faces this challenging situation in reality or in the imaginary process, three factors happen: the event itself, his perception and the body's reaction to 
the perception of the event. At this moment, when you feel that the event is beyond your capacity, the body reacts automatically, preparing itself to fight or escape and it is this stress reaction that causes the dysfunction [9].

Thus both treatments influence each other, after a physiological evaluation performed by the urologist, an evaluation by the psychologist, a specialist in sexuality, as an integral and necessary part of the process, is fundamental. Besides offering information that must be added to the organic vision, it seeks to understand the path that the body and mind come doing, acting together with the patient so that he can achieve a more comprehensive understanding of the problem [10-12].

Neurolinguistic Programming (NLP) has reoriented much of clinical psychology to another direction, much more productive, offering new perspectives for old issues. More importantly, it offers a set of tools and methods that can lead quickly and efficiently to specific and desired results [13]. Besides being born from studies conducted on great therapists such as Fritz Perls, Milton Erickson, Virginia Satir and Gregory Bateson; it has also connected with other perspectives such as the systemic constellation, the social panorama, enabling a systemic view of the patient [14].

It becomes essential to perceive the systemic nature of the patient's relationship difficulties or of his sexual dysfunction. The human sexual experience is made of interactions between external stimuli and internal processes, so to fully understand the process of dysfunction that affects an individual or couple, it is essential to identify the various elements of the experience that constitute the dysfunctional context [15].

The sexual response is a sequence of interrelated and natural stimulus-reaction patterns that involve physiological issues and internal processes. Sexual dysfunction occurs when a natural stimulus elicits in one of the partners an opposite or incongruent reaction with the natural sequence [16]. The current state somehow impedes the progression of the natural stimulus-reaction sequence. In almost all cases, the desired state for sexual functioning is a satisfactory psychophysical experience [17]. Being aware of the verbal and non-verbal communication brought by the patient in the complaint history will allow us to know the sequence of external behaviors and internal processes that make up the AE. Thus it will be possible to understand how the "external stimuli" interact with the internal processes resulting in an undesirable sexual experience [18].

Individuals can also produce within themselves, through internal communication, with very little help from external experience, desired or unwanted internal emotional states [19]. Excessively concerned about failure, they create within themselves a psychic situation of expectation of new failure and begin to visualize the new possibility of sexual intercourse as a "test", adopting a double role: actor and spectator of their own performance [20]. This internal process disturbs and limits the desired experience, generating supervision of his performance in sexual intercourse, where he leaves his role of actor and becomes a spectator of himself. The person becomes extremely disturbed by internal projections, causing the quality of your sexual relationship to drop. It creates a radar that monitors your sexual performance, triggering a performance anxiety, followed by biochemical changes and physiological reactions, such as total inhibition of desire, partial or total loss of erection or premature ejaculation in men or several sexual dysfunctions in women [21]. In the case of erectile dysfunction, this highly anxiogenic situation may prevent the individual from obtaining, maintaining or reobtaining the physiological erectile response. The fear of not having erection can lead the individual to the dysfunctional process, perhaps one of the main mechanisms where only psychological aspects are present [22].

When these people imagine themselves playing the sexual role unsatisfactorily, they feel embarrassed and frustrated - as if the internally generated images had actually occurred. By reacting to these imaginary events instead of relating as what actually happens to them, these people inhibit their behavior and do not risk experiencing the possible imagined embarrassment, thus creating a process of avoiding sexuality [23]. Considering that the success of the sexual experience depends on its complete availability for the sensory experience, for the "here and now", this internal process can be one of the generators of sexual dysfunction [24].

For NLP, the difference between being inside or outside of some situations can determine the success or failure of our actions, behaviors or even physiological responses [25]. The association presupposes an inner state completely given over to the sensations that accompany that sexual experience. On the other hand, in the dissociation the thoughts and feelings related to that experience are out of context, causing the disconnection of the same [26].

The internal processes play an important role in the context of the sexual experience. If the person is distracted, whether thinking about performance or domestic or professional tasks, the intensity of the sexual experience will be drastically diminished, disconnecting the individual from the process of excitement, the quality of foreplay, and the appropriate sexual response. Being connected in the sexual act, conscious and delivered to the situation can lead the man to proper sexual functioning [27].

Each of these subjective internal conflicts is an example of how internal processes can be used to impoverish rather than enrich the individual experience. The essential purpose of therapy in treating such internal conflicts is to turn them into a resource, either individually or globally. Thus, each internal process contributes to the fullness of the total experience, either as a stimulus that leads the individual to the desired experience, or by the sum of another sensory dimension complementary to the experience [28].

Masters and Johnson [29] already affirmed that a specifically traumatic episode has been enough to end the ability of the male individual of sexual intercourse, establishing a pattern of negative psychosocial influence or even a dysfunctional lifestyle for the traumatized man. When a stimulus triggers an undesirable reaction, it is necessary to identify the process and then interrupt it, in order to allow a reaction or point of choice new and more adequate [30].

For someone who wants to solve human problems, the pieces of the puzzle are the structural elements of the experience: attitudes (beliefs), thoughts (internal processes), emotions (subjective states), actions (external behaviours) and physiological reactions. In positive sexual experiences there is an alignment of attitudes, emotions, thoughts, actions and physiological reactions that naturally culminate in pleasure [31]. In dysfunctional sexual experiences some part of the experience is misaligned: whether in beliefs, subjective state, internal process, external behavior or physiological reaction. The organization of internal processes, external behaviors and physiological reactions, experienced by the patient as a problem, is the structure of the current state [32].

The belief system, that is, what the patient believes, is the great framework of any work of change. Beliefs are generalizations constructed based on our family, social and cultural experience. All the meaning given to our experiences is directly linked to our beliefs and values. They determine interpretations of the environment in which we live as well as behavior, abilities, values, identity, and spirituality. If the patient believes that he or she is unable to achieve something, he or she will discover an unconscious way to confirm it [33]. For NLP, beliefs represent an important structure of our behavior. They guide us through life, are our guiding principles and make us evolve, advance, reach somewhere. On the other hand, they can also make us stop, hesitate, avoid, give up. When we believe in something - positive or negative - our behavior is congruent with this belief [34]. 
The human experience is the result of the interaction between the external world and what our senses perceive. Just as the external world is captured by our senses, it can be recreated internally by them. Those responsible for this codification of what occurs in the external world are our visual, auditory and kinesthetic (tactile, olfactory, gustatory) representative systems, that is, our internal and external communication is based on our senses; the subjectively generated images, internal dialogue, smells and tastes, sounds and feelings that our mind produces; and the various external behaviors generated to act directly in the world $[35,36]$.

We constantly use representative systems to capture information from the external world, to think and plan our actions. In this way, it becomes important to understand the main system used by the patient in the sexual experience, which can be evaluated through the words used more frequently, the way he experiences the process of excitement, which is directly connected to his most developed system of capture, conscious or not [37].

Another important distinction to be made is to verify if the system of conduct, the one where the subjective processes are prioritized and verified through the observation of the access tracks of the stored information, is inside or outside the individual consciousness. That is, if the person can see the picture generated internally, feel the sensations generated internally, or hear the sounds and words generated internally, which produce the experience. In general, the conduct system of people seeking therapy is outside the consciousness [38]. When the system that characteristically generates the experience (the system of conduct) is outside of consciousness, it becomes impossible for the individual to make choices regarding the type of experience that will be generated: the internally generated experiences are out of control. Here the patient generates subjective images that will fail again. This process is especially out of control when he is not conscious of his own subjective imaginary [39].

In cases of sexual dysfunction, understanding the internally generated experience is often found in one of the polarities, while the external sensory experience remains at the other end [40]. If we can control the internal experience in a way that generates positive fantasies congruent with the external sensory experience in progress, we can create an alignment between the internal and external experiences of the sexual experience [41]. A diluted mixture of congruent internal fantasy and external sensory experience is a maximum focus of the consciousness on the intense externally generated experience produced during a sexual encounter. Sexuality is an essential pillar of the human emotional universe and is present in all phases of life, from birth to death [42]. Many people still treat sexual behavior as if it were not part of global human behavior. It is a great distortion to consider sexuality as something separate from the whole human system. To understand sexual dysfunction, it is necessary to understand the whole context. It is fundamental to recognize that human behavior and sexual expression are not separated from the rest of the human experience, and then to integrate sex and marital therapy into general treatment programs [43, 44].

\section{Conclusion}

Human sexuality occupies a privileged place in the fields of psychotherapy. Unlike other psychological demands, in which the therapist has the responsibility to interpret behavior as progress or relapse, here the success or failure achieved with sexual therapy is perceptible and visible. The physiological reaction of the patient clearly demonstrates whether or not the desired changes have been achieved.

As body and mind form a single system and both influence each other, a systemic and multidisciplinary look at sexual dysfunctions is essential.

\section{References}

1. Burnett, A. L., Nehra, A., Breau, R. H., Culkin, D. J., Faraday, M. M., Hakim, L. S., ... \& Shindel, A. W. (2018). Erectile dysfunction: AUA guideline. The Journal of urology, 200(3), 633641.

2. Kingsberg, S. A., \& Althof, S. E. (2018). Psychological management of hypoactive sexual desire disorder. Textbook of Female Sexual Function and Dysfunction, 53-57.

3. Cavalcanti R, Cavalcanti M. (2012). Erectile Dysfunction. In R. Cavalcanti \& M. Cavalcanti (Eds), Clinical treatment of sexual inadequacies (pp. 251-286). São Paulo: Roca.

4. Reisman, Y. \& Nobre, P. J. (2021). Male Sexual Dysfunctions. In Psychiatry and Sexual Medicine (pp. 135-160). Springer, Cham.

5. Rosen, R. (2003). Looking beyond erectile dysfunction: the need for multi-dimensional assessment of sexual dysfunction. European Urology Supplements, 2(10), 9-12.

6. Sharma, A., \& Sharma, R. P. (2019). Erectile Dysfunction: The Male Stigma. International Journal of Surgery and Medicine, 5(3), 172-178.

7. Langer, R., Langer, B., Mahajan, R., Sharma, E., Gupta, R. K., \& Kumari, R. (2017). Exploring psychosocial issues in patients of erectile dysfunction: a study in tertiary care setting. International Journal of Medical Science and Public Health, 6(6), 1050-1055.

8. Bossio, J. A., Basson, R., Driscoll, M., Correia, S., \& Brotto, L. A. (2018). Mindfulness-based group therapy for men with situational erectile dysfunction: A mixed-methods feasibility analysis and pilot study. The journal of sexual medicine, 15(10), 1478-1490.

9. Klapilová, K., Demidova, L. Y., Elliott, H., Flinton, C. A., Weiss, P., \& Fedoroff, J. P. (2019). Psychological treatment of problematic sexual interests: cross-country comparison. International Review of Psychiatry, 31(2), 169-180.

10. Martins, I. J. (2018). Early Diagnosis and Nutritional Treatment stabilizes Neuropsychiatric Disorders. Global Journal of Medical Research, 1(1):1-7.

11. Martins, I. J. Anti-Aging Genes Improve Appetite Regulation and Reverse Cell Senescence and Apoptosis in Global Populations. Advances in Aging Research, 2016, 5, 9-26.

12. Yu, W., Wan, Z., Qiu, X. F., Chen, Y., \& Dai, Y. T. (2013). Resveratrol, an activator of SIRT1, restores erectile function in streptozotocin-induced diabetic rats. Asian journal of andrology, 15(5), 646.

13. Sutantoyo, F. F., Sugianto, P., Hamdan, M., \& Nugraha, P. (2021). The Diagnostic Challenges in Patient with Multiple System Atrophy: A Case Report. European Journal of Molecular \& Clinical Medicine, 7(10), 2415-2420.

14. Cameron-Bandler L. (1993).Solutions. Summus Editorial Group.

15. Rajkumar, R. P., \& Kumaran, A. K. (2015). Depression and anxiety in men with sexual dysfunction: a retrospective study. Comprehensive psychiatry, 60, 114-118.

16. Chen, L., Shi, G. R., Huang, D. D., Li, Y., Ma, C. C., Shi, M., ... $\&$ Shi, G. J. (2019). Male sexual dysfunction: a review of literature on its pathological mechanisms, potential risk factors, and herbal drug intervention. Biomedicine \& Pharmacotherapy, 112, 108585.

17. Scott, K. M., \& Hastings, J. A. (2021). Sexual Dysfunction and disability. In Braddom's Physical Medicine and Rehabilitation (pp. 431-446). Elsevier.

18. Miranda, C. T. D., Paula, C. S. D., Palma, D., Silva, E. M. K. D., Martin, D., \& Nóbrega, F. J. D. (1999). Impact of the application of neurolinguistic programming to mothers of children enrolled in a day care center of a shantytown. São Paulo Medical Journal, 117(2), 63-71.

19. Brotto, L., Atallah, S., Johnson-Agbakwu, C., Rosenbaum, T., Abdo, C., Byers, E. S. \& Wylie, K. (2016). Psychological and 
interpersonal dimensions of sexual function and dysfunction. The journal of sexual medicine, 13(4), 538-571.

20. Velurajah, R., Brunckhorst, O., Waqar, M., McMullen, I., \& Ahmed, K. (2021). Erectile dysfunction in patients with anxiety disorders: a systematic review. International Journal of Impotence Research, 1-10.

21. Wentzell, E. (2017). How did erectile dysfunction become "natural"? A review of the critical social scientific literature on medical treatment for male sexual dysfunction. The Journal of Sex Research, 54(4-5), 486-506.

22. Nimbi, F. M., Tripodi, F., Rossi, R., Navarro-Cremades, F., \& Simonelli, C. (2020). Male sexual desire: an overview of biological, psychological, sexual, relational, and cultural factors influencing desire. Sexual medicine reviews, 8(1), 59-91.

23. Nguyen, H. M. T., Gabrielson, A. T., \& Hellstrom, W. J. (2017). Erectile dysfunction in young men-a review of the prevalence and risk factors. Sexual medicine reviews, 5(4), 508-520.

24. Metz, M. E., Epstein, N. B., \& McCarthy, B. (2017). Cognitivebehavioral therapy for sexual dysfunction. Routledge.

25. Jiang, T., Osadchiy, V., Mills, J. N., \& Eleswarapu, S. V. (2020). Is it all in my head? Self-reported psychogenic erectile dysfunction and depression are common among young men seeking advice on social media. Urology, 142, 133-140.

26. O'Connor J. NLP Neurolinguistic Programming Manual: a practical guide to achieve the results. Qualitymark Editora Ltda, 2009.

27. Britto, R., \& Benetti, S. P. D. C. (2010). Anxiety, depression and personality characteristics in men with sexual dysfunction. Revista da SBPH, 13(2), 243-258.

28. Linder-Pelz, S. The Clinical Effectiveness of Neurolinguistic Programming.DE RIJK, Lisa. NLP: Principles in Practice. 2016.

29. Masters W H, Johnson V E. Human sexual response. 1966.

30. Abdo C H N, Afif-Abdo J. (2012). Erectile Dysfunction. In A. Carmita, Human Sexuality and its disorders (pp. 107-142). São Paulo: medical reading.

31. LIANG, Jennifer J.; TSOU, Ching-Huei; DEVARAKONDA, Murthy V. Ground truth creation for complex clinical nlp tasksan iterative vetting approach and lessons learned. AMIA Summits on Translational Science Proceedings, v. 2017, p. 203, 2017.

32. Lane, S. E. (2020). Qualitative Analysis of Neuro-Linguistic Programming Concepts Leaders Might Apply to Improve
Employee Engagement (Doctoral dissertation, Colorado Technical University.

33. Osadchiy, V., Mills, J. N., \& Eleswarapu, S. V. (2020). Understanding patient anxieties in the social media era: qualitative analysis and natural language processing of an online male infertility community. J Med Internet Res, 22(3), e16728.

34. Dilts, R., Hallbom, T., \& Smith, S. (2012). Beliefs: Pathways to health and well-being. Crown House Publishing.

35. Tavares, I. M., Moura, C. V., \& Nobre, P. J. (2020). The role of cognitive processing factors in sexual function and dysfunction in women and men: a systematic review. Sexual medicine reviews.

36. Burri, A., \& Porst, H. (2018). The relationship between penile deformity, age, psychological bother, and erectile dysfunction in a sample of men with Peyronie's Disease (PD). International journal of impotence research, 30(4), 171-178.

37. O'Connor J. NLP workbook: a practical guide to achieving the results you want. Conari Press, 2012.

38. Rastrelli, G., \& Maggi, M. (2017). Erectile dysfunction in fit and healthy young men: psychological or pathological? Translational andrology and urology, 6(1), 79.

39. Hoffmann, H. (2017). Situating human sexual conditioning. Archives of sexual behavior, 46(8), 2213-2229.

40. Sansone, A., Cignarelli, A., Ciocca, G., Pozza, C., Giorgino, F., Romanelli, F., \& Jannini, E. A. (2019). The sentiment analysis of tweets as a new tool to measure public perception of male erectile and ejaculatory dysfunctions. Sexual medicine, 7(4), 464-471.

41. Pozza, C., Giorgino, F., Romanelli, F., \& Jannini, E. A. (2019). The Sentiment Analysis of Tweets as a New Tool to Measure Public Perception of Male Erectile and Ejaculatory Dysfunctions.

42. Kotera, Y, Sweet, M. (2019). Comparative evaluation of neurolinguistic programming. British Journal of Guidance \& Counselling, v. 47, n. 6, p. 744-756.

43. Johnson, S. M, Simakhodskaya, Z, Moran, M. (2018). Addressing issues of sexuality in couples therapy: emotionally focused therapy meets sex therapy. Current Sexual Health Reports, v. 10, n. 2 , p. 65-71.

44. Johansen, R. N., Gaffaney, T. W. (2021). Need Management Therapy (Nmt): A New Science of Love, Intimacy, and Relationships. Archway Publishing.
This work is licensed under Creative Commons Attribution 4.0 License

\section{To Submit Your Article Click Here: Submit Manuscript}

DOI: $10.31579 / 2690-1919 / 173$
Ready to submit your research? Choose Auctores and benefit from:

* fast, convenient online submission
* rigorous peer review by experienced research in your field
* apid publication on acceptance
* unique DOI for all articles
* immediate, unrestricted online access

At Auctores, research is always in progress.

Learn more www.auctoresonline.org/journals/journal-of-clinicalresearch-and-reports 